
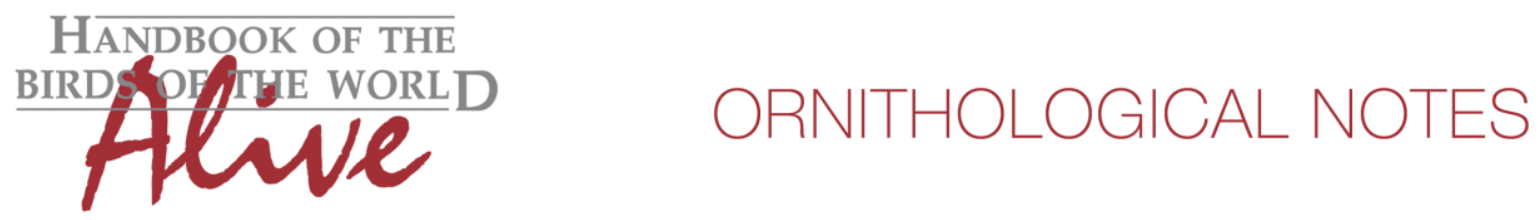

\title{
Notes on the vocalizations of Slaty-capped Flycatcher (Leptopogon superciliaris)
}

\author{
Peter Boesman
}

In the following we briefly analyze and compare voice of the two races of Slaty-capped Flycatcher (Leptopogon superciliaris). We also try to quantify the extent of any vocal differences using the criteria proposed by Tobias et al. (2010), as a support for taxonomic review. We have made use of sound recordings available on-line from Xeno Canto (XC) and Macaulay Library (ML).

Voice of L.s.superciliaris is quite similar over its entire range.

Despite a fairly extensive vocabulary, the vocalization heard mostly by far is a nasal double note "whit!-cha", sometimes in a short series and preceded by a few short introductory notes. This is presumably the day-time song

Voice of L.s. albidiventris seems to be more varied, and a similar double note as superciliaris is often heard as part of a more extensive phrase.

I will compare here this double note solely, although it is not entirely clear if this vocalization has the same function in both races:

\section{L.s.superciliaris $(n=8)$}

Despite quite some variability, the second note is normally short and always downslurred length 1st note length 2nd note $0.05-0.075 \mathrm{~s}$ max. freq. 1st note $0.04-0.19 \mathrm{~s}$ max. freq. 2nd note $1850-2590 \mathrm{~Hz}$ total length $1900-2500 \mathrm{~Hz}$

freq. range $0.21-0.36 \mathrm{~s}$ $1000-1500 \mathrm{~Hz}$

\section{L.s. albidiventris $(n=7)$}

Despite quite some variability, the second note is always rather long and ends upslurred (the second note is actually often distinctly bisyllabic) "whit-t-cheee".

length 1st note

length 2nd note

max. freq. 1st note

max. freq. 2 nd note

total length

freq. range 0.05-0.14s

$0.20-0.36 \mathrm{~s}$

$1600-3400 \mathrm{~Hz}$

$1750-2800 \mathrm{~Hz}$

0.38-0.60s

$750-1800 \mathrm{~Hz}$ 

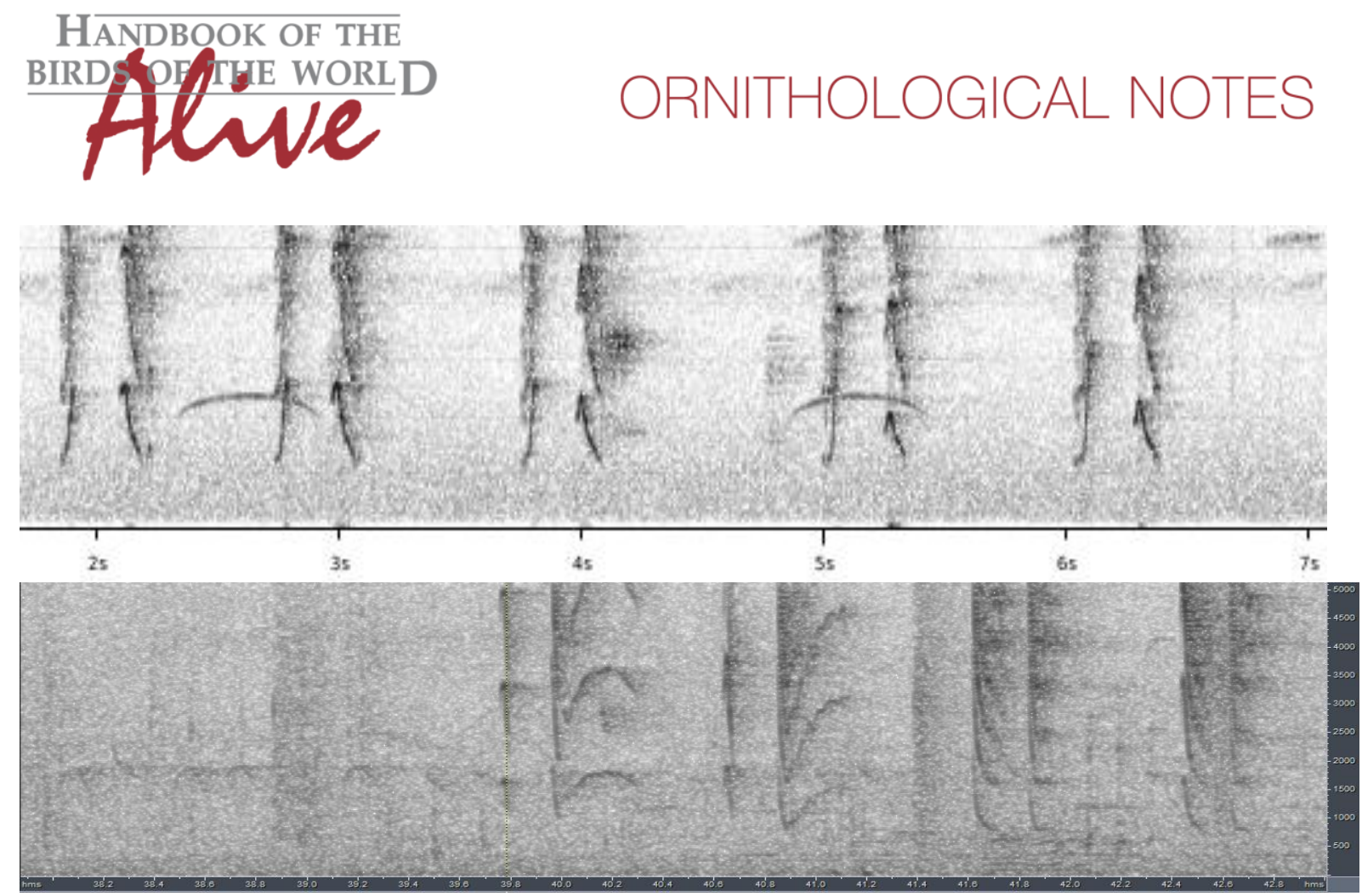

Figure 1: typical day-time vocalization of superciliaris (top) and albidiventris (bottom)

albidiventris differs in having a longer double note (score 2-3), with a longer second note (score 2-3) which is upslurred instead of downslurred (score 1-2). Both races can thus be easily identified. If we apply Tobias criteria on this vocalization, total score for vocal difference would be about 4-5.

This note was finalized on 1st July 2015, using sound recordings available on-line at that moment. We would like to thank in particular the many sound recordists who placed their recordings for this species on XC and ML.

\section{References}

Tobias, J.A., Seddon, N., Spottiswoode, C.N., Pilgrim, J.D., Fishpool, L.D.C. \& Collar, N.J. (2010). Quantitative criteria for species delimitation. Ibis 152(4): 724-746.

\section{Recommended citation}

Boesman, P. (2016). Notes on the vocalizations of Slaty-capped Flycatcher (Leptopogon superciliaris). HBW Alive Ornithological Note 119. In: Handbook of the Birds of the World Alive. Lynx Edicions, Barcelona. (retrieved from http://www.hbw.com/node/932025 on 4 August 2016). 